\title{
Health Information Systems Training for a Countrywide Implementation in Uruguay
}

\author{
A. Margolis', ', A. Vero', L. Bessonart', A. Barbiel', M. Ferla' \\ 'Federación Médica del Interior, Montevideo, Uruguay \\ ${ }^{2}$ Facultad de Medicina, Universidad de la República, Uruguay
}

\begin{abstract}
Summary
Objectives: Health Information systems training is one of the bottlenecks in clinical systems implementation. In this article, a strategy to massively create and train interdisciplinary coordinating teams is described for a project in Uruguay at FEMI, a non-academic setting which indudes 23 health care institutions across the country and a tertiany referral center in Montevideo.

Methods: A series of educational activities were designed for the local coordinating teams. They induded both onsite and online formats, site visits, integrated with some of the project tasks.

Results: In total, 128 professional from all the Institutions participated in one or more of the training sessions (onsite and online) and 87 of them accomplished one of the forms of training. Conclusions: Massive basic health informatics training was possible in Uruguay through collaboration with academic insitiutions at the country and regional level. Next steps indude an active involvement of nurses in the educational events and planning of massive training of end users.
\end{abstract}

Keywords

Uruguay, South America, information systems, inservice training

Yearb Med Inform 2009:153-7

\section{Introduction}

Uruguay is a small country located in the southern cone of South America, with 3.4 million people, half of them living in Montevideo. Its health indicators (e.g., life expectancy of 76.6 years, infant mortality rate of 11.9 deaths / thousand) are close to those of developed economies. The health care system is comprised of public and private not-for-profit providers. The latter cover approximately $60 \%$ of the population and are HMO-type organizations, providing both insurance and health care. There is an on-going health care reform, designed to increase coverage and improve management of the first level of health care.

FEMI (www.femi.com.uy) is a federation of 23 private not-for-profit providers across Uruguay. It covers ap- proximately 650 thousand people and owns a tertiary center in Montevideo.

Pressure from ongoing national changes in health funding and regulation have pushed FEMI to develop a project, in order to improve efficiency in health care through the use of information and communications technologies (ICT). This project is supported by the Inter American Development Bank through the MIF Fund. It aims at the exchange and analysis of administrative and particularly clinical information at a federal level, taking into account the different levels of information system development of each individual institution of FEMI. A general diagram of the proposed system architecture and main lines of action are shown in figures 1 and 2 . The project was officially launched in March 2008.

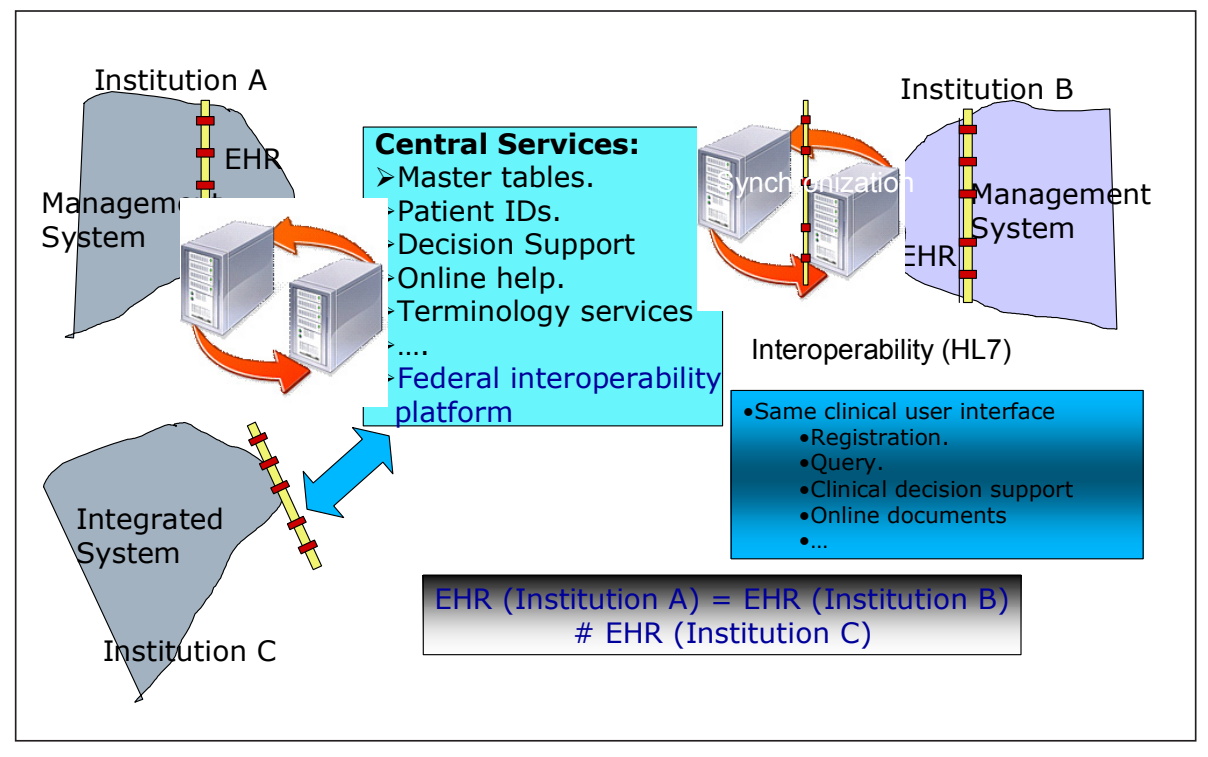

Fig. 1 Model of the federal electronic health record 
Fig. 2 Main lines of action at the FEMI Project

As part of the project, there needs to be interdisciplinary coordinating units at each of the 23 FEMI institutions and the central referral center. These units are ideally integrated by a physician (ideally, the Chief Medical Officer), an information system professional and a medical records technician, and if possible by the health administrators. So, these coordinating units need to be created and trained.

Trained leaders are considered a bottleneck for the successful implementation of health information systems, both in developed and developing economies [1, 2]. A curriculum consistent with existing needs is also required, because health information projects usually need both non-informatics and informatics knowledge, skills and attitudes. Examples of noninformatics attributes needed are project and change management, leadership, and well-developed interpersonal communication; examples of health informatics knowledge required are knowledge of clinical systems functionalities, regulatory and legal environment, standards, coding systems, and so on. The noninformatics skills are frequently poorly covered in existing curricula, with a mismatch between academia and practice.

\section{Description of Interdisciplinary Team Training}

The first training the interdisciplinary units received was intended to provide a basic introduction to the topics and to help create the local units, allowing exchange among them and with the central coordinating unit. A face-to-face short course was then designed and carried out.

There was experience by the Uruguayan Health Informatics Society SUIS (www.suis.org.uy) in the provision of introductory courses on health information systems, in agreement with the School of Medicine and School of Engineering of the Universidad de la República [3]. Therefore, FEMI agreed with SUIS to organize an introductory course tailored for and integrated into FEMI's project needs. It was accredited as a Continuing Medical Education activity by the School of Medicine with 20 credits.

The course was designed to provide a basic introduction to health information systems. Some of the topics covered were health informatics project management, change management, electronic medical record systems, human error prevention through system redesign, cod- ing systems, health information standards, and data warehouses (table 1).

It had 21 hours of face-to-face lectures and small-group workshops (divided into three 7-hour sessions separated by a month or more), readings, a course Web page, and exercises done by each local interdisciplinary team, integrated into the project. The first exercise was to diagnose the current status of hardware, software applications, and communications in each health care institution. The second was to propose functionalities for the federal system, based on existing institutional needs and what they had learned from the course.

There were optional benchmarking activities: first, a three-day visit to two institutions in Buenos Aires, Argentina, with long-standing clinical information systems in place; second, a one-day visit to the Uruguayan Social Security Clinical Information Systems, which are advanced in relation to the rest of the institutions in the country.

Other training for the local coordinating units during 2008 were mainly online, provided through agreements with regional academic institutions, and included an introductory three-month online course, called "10 x 10", provided by the Hospital Italiano de Buenos Aires, AMIA and the Oregon's Health Informatics Program [4], an HL7 threemonth online course aimed at FEMI's informatics professionals and provided by HL7 Argentina (figures 3 and 4). Both of them implied approximately 100 hours of coursework.

Table 1 Topiss covered in the introductory course

Project Management
Change Management
Human error and patient safety
Integrated health information systems and clinical
information systems (electronic health records and
prescribing)
Coding systems, standards and regulations
Examples of clinical information system implementations
Data Warehouses and Management information systems
Virtual libraries




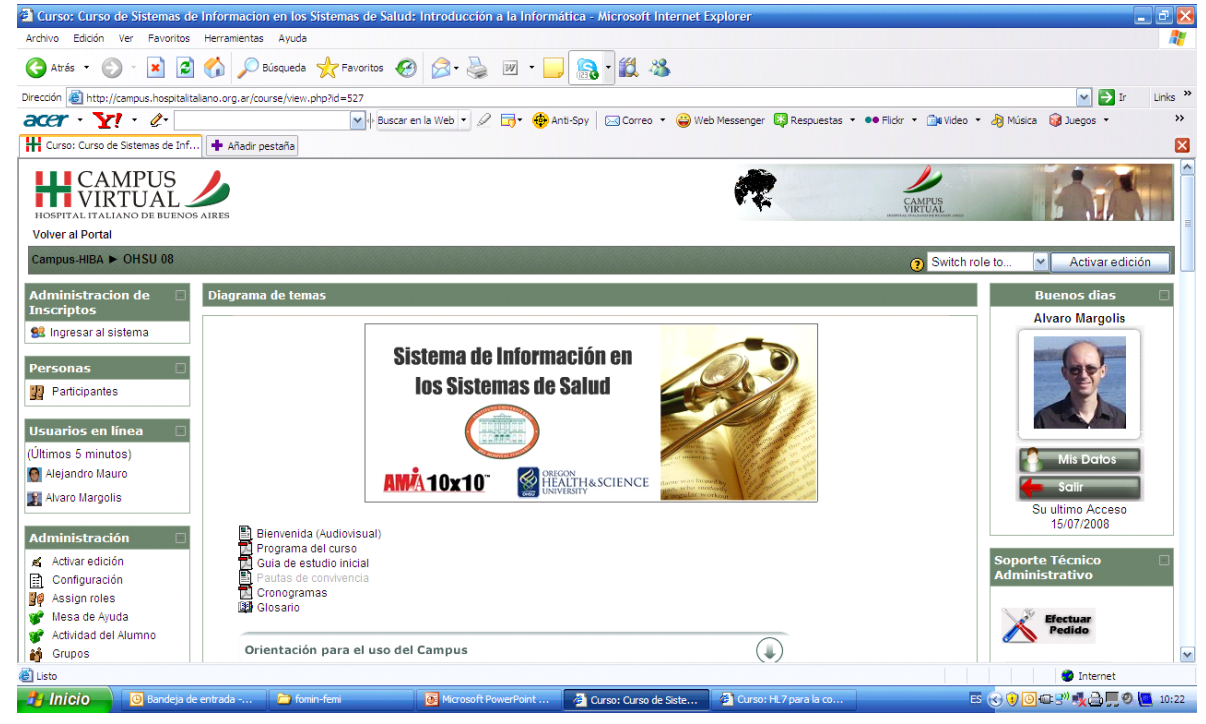

Fig. $310 \times 10$ introductory course portal

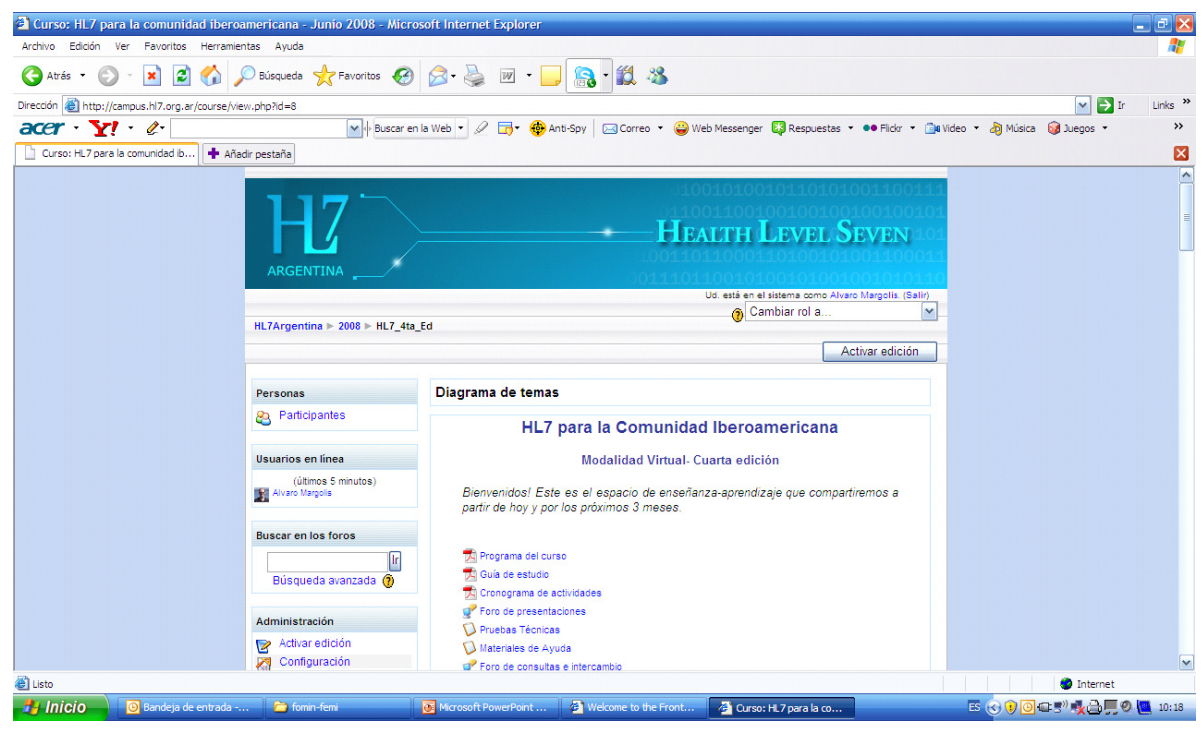

Fig. 4 HL7 course portal

\section{Results}

\section{Introductory Course and Other Onsite Events}

Regarding the results of this course, an average of 60 professionals with different backgrounds (see table 2) from all the 23 institutions attended each of the three 7-hour sessions, and 31 of them went to the site visits in Buenos Aires. Thirty-seven of them, coming from 14

institutions representing 12 different jurisdictions of Uruguay, fulfilled the requirements to pass the course (attendance + homeworks, see table 2 and figure 5).

The overall rating of the course by participants was very positive: $4 / 5$ $(55 \%)$ and $5 / 5(42 \%)$. Some comments included to continue with frequent sessions on related topics, to learn more in detail some of the topics covered, and to communicate electronically in between face-to-face sessions.
Following the introductory course, there were other regular face-to-face events with the coordinating units, including site visits to clinical implementations in Uruguay and participation in Health Informatics Conferences in Uruguay and Argentina, such as InfoLAC 2008, the Regional Congress of Medical Informatics.

\section{Online Courses}

Regarding the other activities for the local coordinating units, the " 10 x 10 " program had 27 professionals taking it, and the HL 7 course had 40 professionals enrolled in it. In this case, there was a segmentation of the audience, according of the professional profile (see table 2).

In total, 128 professionals from all the Institutions participated in one or more of the training sessions (onsite and online) and 87 of them accomplished one of the forms of training.

A request for suggestions regarding future events was asked for, and the participants proposed:

- To learn more about standards, particularly HL7.

- To continue learning about clinical functionalities of health information systems.

- To discuss practical problems.

- To visit more implementation sites.

- To have face-to-face interaction with the online teachers.

- To have a face-to-face event in preparation of the distance modules, in order to be prepared to use the learning platform.

- To have protected time to study at work.

\section{Discussion}

The International Medical Informatics Association IMIA has published guidelines for health informatics education at the user and expert level [5]. These guidelines are currently being updated. Nevertheless, leadership in clinical in- 
Table 2 Profile of participants in training events

\begin{tabular}{|c|c|c|c|c|c|}
\hline & $\begin{array}{l}\text { Total number of } \\
\text { participants }\end{array}$ & & & & \\
\hline & & Physicians & Administration & $\begin{array}{l}\text { Informatics } \\
\text { professionals }\end{array}$ & $\begin{array}{l}\text { Medical records } \\
\text { personnel }\end{array}$ \\
\hline \multicolumn{6}{|l|}{ Introductory course } \\
\hline $\begin{array}{l}\text { Participated in one or more } \\
\text { of the sessions }\end{array}$ & 96 & 44 & 15 & 27 & 10 \\
\hline Fulfilled the course criteria & 37 & 18 & 5 & 10 & 4 \\
\hline 10x10 (attended) & 27 & 16 & 1 & 4 & 6 \\
\hline HL7 (attended) & 40 & 2 & & 38 & \\
\hline $\begin{array}{l}\text { Total number of professionals } \\
\text { who participated in any event }\end{array}$ & 128 & & & & \\
\hline $\begin{array}{l}\text { Total number of professionals } \\
\text { who completed the intro- } \\
\text { ductory course and/or took } \\
\text { nnv nf the nnline rnirses }\end{array}$ & 87 & & & & \\
\hline
\end{tabular}

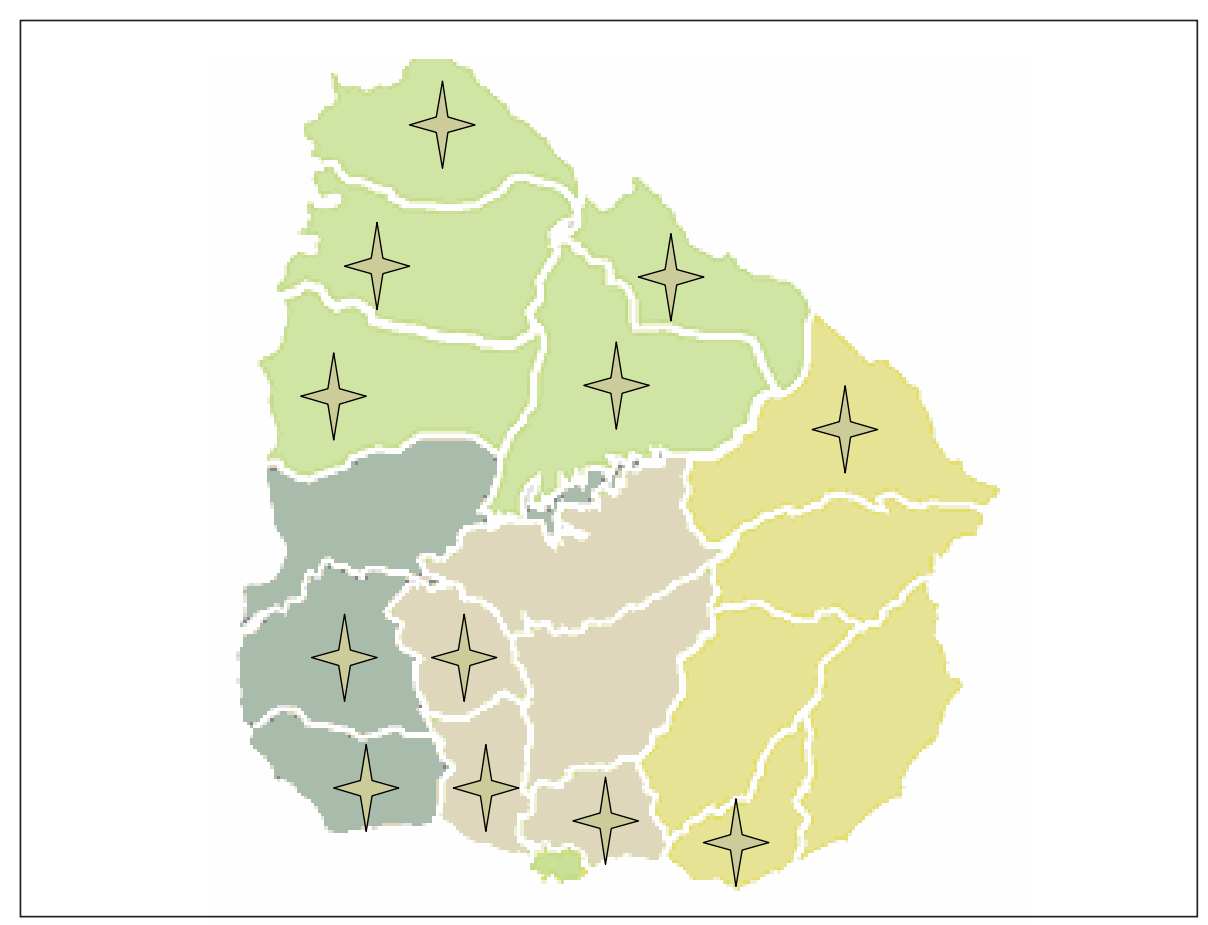

Fig. 5 Map of Uruguay: Geographical representation of attendants who completed the introductory course

formation systems implementation sometimes needs respected health care professionals with basic health informatics knowledge and skills, in areas related to project and change management, coding systems, and clinical systems functionalities [1]. These have been addressed in the USA by intro-
1) they are designed to be interdisciplinary, as the different professions are required to interact during classes, workshops and outside class, for homework, thus strengthening the need for teamwork; 2) the educational activities are integrated smoothly into a health information system implementation, as it helps create and train the local units, develop the sense of community with the rest of the units and the central coordination as part of the change management process, and the exercises are designed to be an input for the first stage of the project. It is planned to heavily include nurses in next training activities, as clinical systems deployment is closer.

It should also be stressed the massive dimension of this training effort for Uruguay: for example, the population of the USA is 100 times larger than that of Uruguay, so if we multiply 87 professionals trained at FEMI by 100 , the number ( 8700 professionals) is close to the goal of the American Medical Informatics Association, in having 10 thousand professionals trained in the US by 2010 (by the introductory $10 \times 10$ course).

\section{Future Steps}

During 2009, there will be similar online and face-to-face courses for other members of the coordinating units. There will also be events for nurses, as their participation is very important in the implementation of clinical systems. Finally, clinical end-user training will be designed, conceptually similar to that implemented by the American Medical Informatics Association, called "Digital Patient Record Certification Examination and Study Guide" [7]. leading to degree-granting programs. There is experience in the adaptation of one of such courses to the Latin American reality [4].

The courses described in this article and the other training activities add to previously published experiences in:

\section{Conclusion}

Massive basic health informatics training was possible in Uruguay through 
collaboration with academic institutions at the country and regional level, using face-to-face and online learning modalities. Trained leaders are in turn necessary for a successful and widespread implementation of clinical information systems.

\section{Acknowledgements}

This project is partially funded by the Inter American Development Bank, through its Multilateral Innovation Fund (http://www.iadb.org), project UR-M1021, "Productivity and Management Improvements in Healthcare System".

We acknowledge the help of Ms. Magdalena Hourcade in gathering the data for this article. We would also like to specially thank the academic institutions, SUIS, Hospital Italiano de Buenos Aires and HL7 Argentina, which made this training possible, as well as the site visits to Hospital Austral in Argentina and Instituto de Seguridad Social in Uruguay.

Note: An abstract of this article was presented at the Meeting of the IMIA Education Working Group, in Buenos Aires, Argentina, October 2008.

\section{References}

1. Hersh W. Health and Biomedical Informatics: Opportunities and Challenges for a Twenty-First Century Profession and its Education. Geissbuhler A, Kulikowski C, editors. IMIA Yearbook of Medical Informatics 2008. Methods Inf Med 2008; 47 Suppl 1:157-64

2. Hersh W, Margolis A, Quirós F, Otero P. Determining Health Informatics Workforce Needs in Developing Economies. Rockefeller Foundation Seminar on eHealth Capacity Building, Italy, July 2008. Available at: http://ehealth-connection.org/

3. Sociedad Uruguaya de Informática en la Salud. In "La Informática de la Salud en Iberoamérica", SEIS
Journal, number 64, October 2007

4. Otero P, Hersh W, Luna D, López Osornio A, González Bernaldo de Quirós F. Translation, Implementation and Evaluation of a Medical Informatics Distance Learning Course for Latin America. Poster 421, Medinfo 2007.

5. Recommendations of the International Medical Informatics Association (IMIA) on Education in Health and Medical Informatics. Methods Inf Med 2000;39:267-77.

6. Hersh W, Williamson J. Educating 10,000 informaticians by 2010 : The AMIA $10 \times 10$ program. Int J Med Inform 2007;76:377-82.

7. http://www.amia.org/, visited on December 16 2008.

Correspondence to:

Dr. Alvaro Margolis

Federación Médica del Interior

Cufré 1781

Montevideo Uruguay (P 11200

Tel: +59899689407

Fax: +59824005835

E-mail: margolis@mednet.org.uy 